\title{
Oral Contraceptive Use and Invasive Cervical Cancer
}

\author{
FABIO PARAZZINI, * CARLO LA VECCHIA,*** EVA NEGRI* AND RENATO MAGGIT
}

\begin{abstract}
Parazzini F (Mario Negri Institute for Pharmacological Research, 20157 Milan, Italy), La Vecchia C, Negri E and Maggi R. Oral contraceptive use and invasive cervical cancer. International Journal of Epidemiology 1990; 19: $259-263$.

The relationship between oral contraceptive use and the risk of invasive cervical cancer was investigated using data from a hospital-based case-control study conducted in the greater Milan area, Northern Italy. A total of 367 women under 60 years of age with a histologically confirmed diagnosis of invasive cervical cancer was compared with a group of 323 controls admitted for a spectrum of acute conditions, non-gynaecological, hormonal or neoplestic and apparently unrelated to oral contraceptive use. Cases had used oral contraceptives more frequently than controls, the age-adjusted relative risk (RR) being 1.53 (95\% confidence interval 0.99-2.36). The risk increased with duration of use: compared with never users the age-adjusted RR was 1.48 for up to two years and 1.83 for more then two years $\left(\chi_{1}^{2}=\right.$ $5.28, p=0.02$ ). Allowing for major identified potential confounding factors, including sexual and reproductive habits, by means of multiple logistic regression, did not explain the associaton (multivariate RR 1.85 for ever use, 1.05 for up to two years and 2.47 for more than two years). When the interaction between oral contraceptive use and parity or sexual habits was analysed, the effects of various factors appeared independent: the point estimate for multiparous oral contraceptive users versus nulliparous never users was 8.01. There was no consistent influence on risk of invasive cervical cancer of age at first use, whereas the RRs were slightly greater for women who had first used oral contraceptives less than ten years before or had last used them less than five years before diagnosis: these findings, however, were far from significant.
\end{abstract}

A large number of investigations, including those based on cytology screening programmes, cohort and case-control studies have suggested that the incidence of cervical neoplasms is higher in women who have used oral contraceptives (OC). The estimated relative risks, however, were only moderately increased, and most studies could not adequately allow for major risk factors for cervical neoplasia, chiefly indicators of sexual habits. ${ }^{1-3}$

Several studies have focused on pre-invasive abnormalities $^{4-10}$ which are particularly prone to identification and classification bias, whereas the evidence from studies of invasive cancer is still inconsistent. ${ }^{12} \mathrm{~A}$ cohort study from Britain ${ }^{11}$ as well as two case-control studies (one from US ${ }^{12}$ and one from eight different countries $^{13}$ ) have shown significantly elevated risks among long-term oral contraceptive users, but no noticeable association emerged from other studies conducted in the US ${ }^{14}$ and Central America. ${ }^{15}$

To provide further information on the issue, we

\footnotetext{
* 'Mano Negri' Institute for Pharmacological Research, via Eritrea 62, 20157 Milan, ltaly.

* Institute of Social and Preventive Medicine, University of Lausanne, 1005 Lausanne, Swizzerland.

† First Obstetries and Gynecology Clinic, University of Milan, 20100 Milan, Italy.
}

present here the updated results from a case-control study conducted in Northern Italy. The availability of information on major recognized risk factors for cervical cancer permitted careful examination of their confounding, modifying effects and interactions.

\section{SUBJECTS AND METHODS}

Since 1981 we have conducted a case-control study of cervical neoplasia. The design of this investigation has already been described. ${ }^{16.17}$ Briefly, trained interviewers identified subjects from hospital logs and clinical records and questioned cases and controls using a standard questionnaire.

Information was obtained on personal characteristics and habits, gynaecological and obstetric data, related medical history, general indicators of sexual habits (age at first intercourse, total number of sexual partners), and a detailed history of lifetime use of oral contraceptives and other female hormones. Despite the rather sensitive nature of the interview, less than $2 \%$ of cases and controls refused to be interviewed, reflecting a particularly favourable attitude towards epidemiological data collection among patients in Italy.

Cases were women younger than 60 years with a histologically confirmed diagnosis of invasive cervical 
cancer ( 367 subjects: median age 47 years, range 22 59) made in the year prior to interview, admitted to the Obstetrics and Gyneacology Clinics of the University of Milan, to the National Cancer Institute and the 'Ospedale Maggiore' of Milan (including the four largest teaching and general hospitals in Milan).

Controls were patients admitted for acute conditions to the 'Ospedale Maggiore' in Milan and several specialized University Clinics. Women were not included if they had been admitted for gynaecological, hormonal or neoplastic disease or had undergone hysterectomy. A total of 323 controls aged 20-59 (median age 47 years) were included in the analysis; of these, $25 \%$ were admitted for traumatic conditions (mostly fractures and sprains), $28 \%$ for non-traumatic orthopaedic disorders (mostly low back pain and disc disorders), $20 \%$ for surgical conditions (mostly abdominal, such as appendicitis or strangulated hernia), and $27 \%$ for other illnesses such as ear, nose, throat and dental disorders. They were blind for the purpose and goals of the study (specifically the relation between $\mathrm{OC}$ use and cervical cancer).

The current report is based on data obtained before December 1987.

\section{Data Analysis}

We computed the relative risks (RR) of invasive cervical cancer, together with their $95 \%$ confidence intervals $(\mathrm{CI}),{ }^{18}$ from data stratified for quinquennia of age by the Mantel-Haenszel procedure. ${ }^{19}$ When a factor could be classified in more than two levels, the significance of the linear trend was assessed by the Mantel test. ${ }^{20}$

In order to allow simultaneously for the effects of several potential confounding factors, unconditional logistic regression, with maximum likelihood fitting, ${ }^{21}$ was used. Included in the regression equations were terms for age, marital status, education, parity, number of sexual partners, age at first intercourse, cigarette smoking, history of Pap smears and use of barrier contraceptive methods.

\section{RESULTS}

The distribution of cases and controls according to age, socio-demographic indicators, parity, sexual habits, lifetime frequency of Pap smears and use of barrier contraceptive methods is presented in Table 1 .

Women with invasive cervical cancer were more frequently married, parous and less educated, had a greater number of sexual partners, earlier age at first intercourse, reported less frequent and less recent Pap smears and less frequent use of barrier methods of contraception.
The relation of various measures of $\mathrm{OC}$ use with invasive cervical cancer is considered in Table 2. Cases had used OC more frequently than controls, the ageadjusted RR being 1.53. The risk increased with duration of use: compared with never users, the ageadjusted RRs were 1.48 and 1.83 respectively for less than two years and two years or more. This trend in risk was statistically significant.

There was no consistent influence on risk of invasive cervical cancer of age at first use, whereas the RRs were slightly greater for women who had first used OC less than ten years before diagnosis or had last used them less than five years before diagnosis; these differences, however, were far from significant.

The multivariate $R R$ values tended to be higher than

TABLE 1 Distribution of 367 cases of invasive cervical cancer and 323 controls" according to age and selected covariates." Milan, Italy, $1981-87$

\begin{tabular}{|c|c|c|c|c|}
\hline \multirow[b]{2}{*}{ Covariates } & \multicolumn{2}{|c|}{ Cervical cancer } & \multicolumn{2}{|c|}{ Controls } \\
\hline & Number & $\%$ & Number & $\%$ \\
\hline \multicolumn{5}{|l|}{ Age (years) } \\
\hline$<40$ & 86 & 23.4 & 92 & 28.5 \\
\hline $40-49$ & 117 & 319 & 90 & 27.9 \\
\hline $50-59$ & 164 & 44.7 & 141 & 43.7 \\
\hline \multicolumn{5}{|l|}{ Marital status } \\
\hline Never married & 28 & 76 & 45 & 13.9 \\
\hline Ever married & 339 & 92.4 & 278 & 861 \\
\hline \multicolumn{5}{|l|}{ Education (years) } \\
\hline$<7$ & 263 & 71.7 & 175 & 54.2 \\
\hline $7-11$ & 72 & 19.6 & 94 & 29.1 \\
\hline$\geq 12$ & 32 & 8.7 & 54 & 16.7 \\
\hline \multicolumn{5}{|l|}{ Parity } \\
\hline 0 & 28 & 7.6 & 69 & 21.4 \\
\hline $1-2$ & 181 & 49.3 & 189 & 58.5 \\
\hline$\geq 3$ & 158 & 43.1 & 65 & 20.1 \\
\hline \multicolumn{5}{|l|}{$\begin{array}{l}\text { Number of sexual } \\
\text { partners }\end{array}$} \\
\hline $0-1$ & 271 & 73.8 & 267 & 82.7 \\
\hline$\geq 2$ & 91 & 24.8 & 46 & 14.2 \\
\hline unreported & 5 & 1.4 & 10 & 3.1 \\
\hline \multicolumn{5}{|c|}{$\begin{array}{l}\text { Age at first intercourse } \\
\text { (years) }\end{array}$} \\
\hline$<18$ & 70 & 19.1 & 25 & 7.8 \\
\hline $18-20$ & 139 & 37.9 & 100 & 31.3 \\
\hline$\geqslant 21$ or never & 158 & 43.1 & 195 & 60.9 \\
\hline \multicolumn{5}{|c|}{ Number of Pap smears } \\
\hline 0 & 241 & 65.7 & 98 & 30.3 \\
\hline$\geq 1$ & 126 & 34.3 & 225 & 69.7 \\
\hline \multicolumn{5}{|c|}{ Time since last smear } \\
\hline$<5$ years & 80 & 21.8 & 185 & 57.3 \\
\hline$>5$ or never & 287 & 78.2 & 138 & 42.7 \\
\hline \multicolumn{5}{|c|}{$\begin{array}{l}\text { Use of barrier } \\
\text { contraceptive methods }\end{array}$} \\
\hline Never used & 344 & 93.7 & 286 & 88.5 \\
\hline Ever used & 23 & 6.3 & 37 & 11.5 \\
\hline
\end{tabular}

*In some cases the number of various strata do not add to the total owing to a few missing values. 
TABLE 2 Relative risk of invasive cervical cancer in relation 10 various measures of oral contraceptive use. Milon, Italy, 1981-87

\begin{tabular}{|c|c|c|c|c|}
\hline & \multirow{2}{*}{$\begin{array}{l}\text { Cervical } \\
\text { cancer }\end{array}$} & \multirow[b]{2}{*}{ Controls } & \multicolumn{2}{|c|}{$\begin{array}{l}\text { Relative risk estimates } \\
\qquad(95 \% \mathrm{Cl})\end{array}$} \\
\hline & & & $\mathbf{M}-\mathrm{H}^{*}$ & MLR** \\
\hline \multicolumn{5}{|c|}{ Ever use } \\
\hline No & 298 & 276 & $1 \dagger$ & $1+$ \\
\hline Yes & 69 & 47 & $\begin{array}{c}1.53 \\
(0.99-2.36)\end{array}$ & $\begin{array}{c}1.85 \\
(1.00-314)\end{array}$ \\
\hline \multicolumn{5}{|c|}{$\begin{array}{l}\text { Duration of use } \\
\text { (years) } f\end{array}$} \\
\hline$\leqslant 2$ & 36 & 27 & $\begin{array}{c}148 \\
(0.87-2.69)\end{array}$ & $\begin{array}{c}1.05 \\
(0.84-3.24)\end{array}$ \\
\hline$>2$ & 33 & 20 & $\begin{array}{c}1.83 \\
(1.00-334)\end{array}$ & $\begin{array}{c}2.47 \\
(1.19-513)\end{array}$ \\
\hline \multicolumn{5}{|c|}{$\begin{array}{l}\text { Age at first use } \\
\text { (years) }\end{array}$} \\
\hline$<25$ & 17 & 13 & $\begin{array}{c}1.49 \\
(0.68-3.26)\end{array}$ & $\begin{array}{c}2.41 \\
(0.98-5.93)\end{array}$ \\
\hline $25-29$ & 21 & 14 & $\begin{array}{c}172 \\
(0.92-3.60)\end{array}$ & $\begin{array}{c}1.67 \\
(0.74-3.77)\end{array}$ \\
\hline$>30$ & 31 & 20 & $\begin{array}{c}1.43 \\
(0.79-2.60)\end{array}$ & $\begin{array}{c}123 \\
(0.62-2.44)\end{array}$ \\
\hline \multicolumn{5}{|c|}{$\begin{array}{l}\text { Time since first } \\
\text { use (years) }\end{array}$} \\
\hline$<10$ & 39 & 25 & $\begin{array}{c}1.86 \\
(1.02-339)\end{array}$ & $\begin{array}{c}1.98 \\
(1.01-389)\end{array}$ \\
\hline$\geqslant 10$ & 30 & 22 & $\begin{array}{c}1.28 \\
(0.72-2.29)\end{array}$ & $\begin{array}{c}128 \\
(0.67-2.45)\end{array}$ \\
\hline \multicolumn{5}{|c|}{$\begin{array}{l}\text { Time since last } \\
\text { use (years) }\end{array}$} \\
\hline$<5$ & 22 & 12 & $\begin{array}{c}2.06 \\
(0.96-442)\end{array}$ & $\begin{array}{c}1.69 \\
(0.78-368)\end{array}$ \\
\hline$\geq 5$ & 47 & 35 & $\begin{array}{c}1.47 \\
(0.86-2.51)\end{array}$ & $\begin{array}{c}1.53 \\
(0.86-2.73)\end{array}$ \\
\hline
\end{tabular}

* Mantel-Haenszel estimates adjusted for age.

**Estimates from multiple logistıc regression equations including terms for age, marital status, education, parity, number of sexual partners, age at first intercourse, cigarette smoking, history of Pap smears and use of barrier methods of contraception.

†Reference category.

$\ddagger$ Test for trend age adjusted $\chi_{1}^{2}=5.28 p=0.02$; multivariate $\chi_{1}^{2}=7.24$ $\mathrm{p}=0.007$.

the ones adjusted for age only. The point estimate for ever use was 1.85 , and 2.47 for more than two years, both being statistically significant. The multivariate risks in relation to age at first use tended to decrease with later age. This, however, should be considered within the context of the complex interaction between various temporal factors (age, time since first and last use).

The interaction between OC use and the other major risk factors for cervical cancer in this study (ie parity and number of sexual partners) is considered in Table 3. The RR for OC use was elevated in subsequent strata of parity and number of sexual partners. Consequently, the effect of the factors considered appeared independent. Compared with never user nulliparous women, the point estimate rose to 8.01 for OC users with three births or more.

Finally, the relative risks were not significantly heterogeneous in various strata of age, socioeconomic factors, parity, sexual habits, time since last Pap smear and use of barrier methods of contraception, most of the estimated values being above unity (Table 4).

\section{DISCUSSION}

According to these results, women who had used OCs more frequently experienced invasive cervical cancer. The risk increased with duration of use and was about double in OC users for more than two years.

Diagnostic bias (OC users tend to be more frequently screened by Pap smear and consequently more easily diagnosed for cervical neoplasia) has been claimed as a major problem in the interpretation of the association between OCs and cervical pre-invasive neoplasms. ${ }^{3}$ However, it is conceivable that if $\mathrm{OC}$ users preferentially attended screening clinics, they would be more likely to be diagnosed in an early stage of the process of carcinogenesis, thus artificially lowering the frequency of $\mathrm{OC}$ users among invasive cases.

Likewise, separate analyses or simultaneously allowing for lifetime Pap smear frequency, time from last Pap and several other potential confounding factors (including socioeconomic status, sexual habits and reproductive variables) did not show any appreciable interaction or materially change the risk estimates. Indeed the relative risks, if any, tended to increase after multiple adjustment. Plausible explanation for this finding is the effect of social class, which is inversely related with invasive cervical cancer, but directly with $\mathrm{OC}$ use in this population ${ }^{22}$ and the more frequent use of screening by OC users.

Finally, selection bias should not influence these

TABLE 3 Interaction between parity, number of sexual parners and oral coniraceptive use of cervical cancer. Milan, Italy, 1981-87

\begin{tabular}{|c|c|c|}
\hline & \multicolumn{2}{|c|}{ Relative risks* $(95 \% \mathrm{Cl})$ for oral contraceptive use } \\
\hline & Never & Ever \\
\hline \multicolumn{3}{|c|}{ Parity } \\
\hline 0 & $1 \dagger$ & $2.27(0.60-8.58)$ \\
\hline $1-2$ & $2.42(1.44-4.06)$ & $3.62(1.69-7.75)$ \\
\hline$\geq 3$ & $5.66(3.26-9.80)$ & $8.01(3.55-18.06)$ \\
\hline \multicolumn{3}{|c|}{$\begin{array}{l}\text { Number of sexual } \\
\text { partners }\end{array}$} \\
\hline $0-1$ & $1+$ & $1.20(0.72-1.99)$ \\
\hline 2 & $1.55(0.90-2.67)$ & $2.41(0.78-7.45)$ \\
\hline$>3$ & $2.52(1.26-5.05)$ & $4.29(1.45-12.69)$ \\
\hline
\end{tabular}

- Mantel-Haenszel estimates adjusted for age.

tReference category. 
TABLP 4 Relative risk of invasive cervical cancer according to ever use of oral contraceptives and selecied covariates. Milan, Italy, 1981-87

\begin{tabular}{|c|c|}
\hline Covariates & $\begin{array}{c}\text { Relative risk } \\
\text { estimates }(95 \% \mathrm{Cl})\end{array}$ \\
\hline \multicolumn{2}{|l|}{ Age (years) } \\
\hline$<40$ & $1.49(0.80-2.79)$ \\
\hline $40-49$ & $1.77(0.84-3.73)$ \\
\hline $50-59$ & $3.04(0.40-349)$ \\
\hline \multicolumn{2}{|l|}{ Mantal status } \\
\hline Never married & $0.78(022-2.85)$ \\
\hline Ever married & $1.54(0.97-2.44)$ \\
\hline \multicolumn{2}{|l|}{ Education (years) } \\
\hline$<7$ & $1.53(0.84-278)$ \\
\hline $7-11$ & $2.67(1.07-6.65)$ \\
\hline$\geqslant 12$ & $1.06(036-3.06)$ \\
\hline \multicolumn{2}{|l|}{ Parity } \\
\hline 0 & $2.27(0.60-8.58)$ \\
\hline $1-2$ & $1.24(0.68-2.27)$ \\
\hline$\geqslant 3$ & $1.11(0.47-262)$ \\
\hline \multicolumn{2}{|c|}{ Number of sexual partners } \\
\hline $0-1$ & $1.20(0.72-1.99)$ \\
\hline 2 & $2.29(0.49-10.59)$ \\
\hline$\geq 3$ & $2.13(0.53-8.62)$ \\
\hline \multicolumn{2}{|c|}{ Age at first intercourse (years) } \\
\hline$<18$ & $1.10(0.33-3.60)$ \\
\hline $18-20$ & $1.36(0.66-277)$ \\
\hline$\geqslant 21$ or never & $1.28(0.63-2.61)$ \\
\hline \multicolumn{2}{|c|}{ Time since last Pap smear } \\
\hline$<5$ years & $1.75(0.89-3.47)$ \\
\hline 25 years & $2.49(1.20-5.17)$ \\
\hline \multicolumn{2}{|c|}{ Ever use of barrier contraceptive methods } \\
\hline Yes & $1.04(0.29-3.73)$ \\
\hline No & $1.66(1.03-2.66)$ \\
\hline
\end{tabular}

* Mantel-Haenszel estimates adjusted for age.

results, since cases and controls were identified in institutions covering a broadly comparable catchment area and, despite the sensitive nature of the interview, participation in the study was almost complete.

Thus, the present study adds further evidence to the hypothesis of a positive association between cervical cancer and oral contraceptives. Although the evidence is not totally consistent, the two largest studies, conducted in the US ${ }^{12}$ and eight different countries, ${ }^{13}$ reported an approximately $50 \%$ higher risk of invasive cervical cancer among long-term OC users, which was not explained by allowing for the potential effects of major covariates, including indicators of sexual habits, which were suspected to exert a major confounding effect.

Interpretation of these findings in biological terms is largely tentative. There is some suggestion in the present as well as in previous work that the relative risk is higher in the short term, and decreases with time since first and last use. Within the framework of the multistage theory of carcinogenesis this would suggest a later stage effect, which is common to other hormonal- related factors, for example the role of oestrogens in endometrial carcinogenesis. ${ }^{23}$ This also agrees with the observation that oral contraceptives may accelerate the evolution of the pre-invasive condition to invasive neoplasia. $^{24}$

\section{ACKNOWLEDGEMENTS}

This study was conducted within the framework of the CNR (Italian National Research Council) Applied Projects 'Oncology' (contract No. 85.02209.44) and 'Risk Factors for Diseases'. The contributions of the Italian League Against Tumors and of the Italian Association for Research on Cancer, Milan, Italy, are gratefully acknowledged. The authors wish to thank Ms Maria Nigro and Ms Judy Baggott for editorial assistance.

\section{REFERENCES}

' Prentice R L, Thomas D B. On the eptdemiology of oral contraceptives and disease. Adv Cancer Res 1987; 49: 285-401.

${ }^{2}$ Franceschi S, La Vecchia C, Talamini R. Oral contraceptives and cervical neoplasia. Pooled information from retrospective and prospective epidemıologic studies. Tumon 1986; 72: 21-30

${ }^{3}$ Swan S H, Petitti D B. A review of problems of blas and confounding in epidemiologic studies of cervical neoplasıa and oral contraceptive use. Am J Epidemiol 1982; 115: 10-8.

4Thomas D B Relationship of oral contraceptives to cervical carcinogenesis. Obstet Gynecol 1972; 40: 508-18.

${ }^{5}$ Fasal E, Simmons M E, Kampert J B. Factors assoclated with high and low risk of cervical neoplasia. JNCI 1981; 66: 631-6.

${ }^{\circ}$ Clarke E A, Hatcher J, McKeown-Eyssen G E, Lucknsh G M. Cervical dysplasia. Association with sexual behaviour, smoking and oral contraceptive use? Am J Obstet Gynecol 1985; 151: 612-6.

${ }^{7}$ Peritz E, Ramcharan S, Frank J, Brown W L, Huang S, Ray R. The incidence of cervical cancer and duration of oral contraceptive use. Am J Epidemiol 1977; 106: 462-9

'Andolsek L, Kovacic J, Kozuh M, Litt B. Influence of oral contraceptives on the incadence of premalignant and malignant lesions of the cervix. Contraception 1983; 28: 505-19.

${ }^{9}$ Wright N H, Vessey M P, Kenward B, McPherson K, Doll R. Neoplasia and dysplasia of the cervix uteri and contraception: $\mathrm{A}$ possible protective effect of the diaphragm. Br J Cancer 1978; 38: 273-9.

${ }^{10}$ Molına R, Thomas D B, Dabancens A, et al. Oral contraceptives and cervical carcinoma in situ in Chile. Cancer Res 1988; 48: 1011-5.

"Vessey M P, Lawless M, McPherson K, Yeates D. Neoplasia of the cervix uteri and contraception: A possible adverse effect of the pill. Lancet 1983; 2: 930-4.

${ }^{12}$ Brinton L A, Huggins G R, Lehman H F, et al. Long-term use of oral contraceptives and risk of invasive cervical cancer. Int $J$ Cancer 1986; 38: 339-44.

${ }^{13}$ WHO Collaborative Study of Neoplasia and Neoplasia and Steroid Contraceptives. Invasive cervical cancer and combined oral contraceptives. $\mathrm{Br}$ Med J 1985; 290: 961-5.

${ }^{14}$ Celentano D D, Klassen A C. Weisman C S, Rosenshein N B. The role of contracepiive use in cervical cancer: The Maryland cervical cancer case-control study. Am J Epidemiol 1987; 126: $592-604$.

${ }^{15}$ Irwin K L, Rosero-Bixby L, Oberle M W, et al. Oral contraceptives and cervical cancer risk in Costa Rsca. Detection bias or causal association? JAMA 1988; 259: 59-64. 
${ }^{16}$ La Vecchia C, Decarli A, Fasoli M, et al. Oral contraceptives and cancers of the breast and of the female genital tract. Interam results from a case-cont rol study. Br J Cancer 1986; 54: 311-7.

${ }^{17}$ La Vecchia C, Franceschi S, Decarli A, et al. Sexual factors, venereal diseases, and the risk of intraepithelial and invasive cervical neoplasia. Cancer 1986; 58; 935-41.

1 Breslow, N E. Day N E. Statissical methods in cancer research. Vol. 1. The analysis of case-control studies IARC Sci Publ. No. 32. Lyon: IARC, 1980.

${ }^{9}$ Mantel N, Haenszel W. Statistical aspects of the analysis of data from retrospectuve studies of disease. JNCI 1959; 22: 719-48.

${ }^{\mathbf{m}}$ Mantel N. Chi-square tests with one degree of freedom; extensions of the Mantel-Haenszel procedure. J Am Stat Assoc 1963; 58: $690-700$.
${ }^{21}$ Baker R J, Nelder J A. The GLIM System, Release 3. Oxford: Numerical Algorithms Group, 1978.

${ }^{2}$ La Vecchia C, Decarli A, Parazzini F, Gentile A, Negri E, Franceschi $S$. Determinants of oral contraceptive use in Northern Italy. Contraceprion 1986; 34: 145-56.

${ }^{2}$ Pike M C. Age-related factors in cancers of the breast, ovary, and endometrium. J Chron Dis 1987; 40 suppt. 2: 59S-69S.

${ }^{24}$ Stem E, Forsythe A B, Youkeles L, Coffelt C F. Steroid contraceptive use and cervical dysplasia: Increased risk of progression. Science 1977; 196: 1460-2.

(Received November 1989) 